rise further as the $\mathrm{CPhA}$ lobbies to get pharmacists paid for their counselling service. Quebec and Saskatchewan already pay pharmacists about $\$ 16$ per EC consultation - the same rate as a family physician.

"Access is still a big piece," says Madelaine Boscoe, director of the Canadian Women's Health Network. She sees a need for a broad awareness campaign

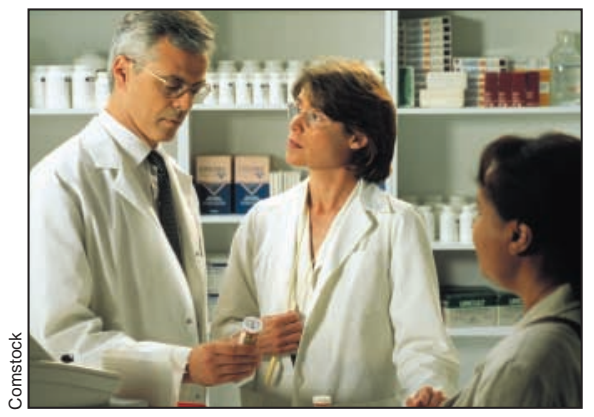

Phamacists have the right to refuse to dispense emergency contraception, but "they have to ensure that the patient is cared for," says the pharmacists association. and a database of pharmacists willing to distribute it as well as a rural distribution method, perhaps through clinics or nurses.

Ultimately, "more access to EC means we are more able to prevent unintended pregnancies," says Linda Capperauld, ED of Planned Parenthood Canada. The $\mathrm{CPhA}$ reports that about $50 \%$ of all pregnancies are unintended, and of those, $50 \%$ are unwanted and half end in abortion. In 2000, over 105000 abortions were performed in Canada. A UK study estimates that increased access to and awareness of EC could result in a halving of the abortion rate.

The new law means Plan B can now be advertised, says Mark Beaudet, at Paladin Labs Inc., the Canadian distributor. Ads will increase awareness and dispel misconceptions, such as the fact that it can be taken within 3 days of unprotected intercourse, not just the morning after.
Obtaining nonprescription status has been a long slog. After years of lobbying, Paladin, the SOGC, CPhA, the College and Women's Capital Corporation asked for priority review of an application to Health Canada. "This is the first time [priority] has been given for rescheduling a drug," says Cooper. There was an "unprecedented response" from some 300 groups.

"It's crazy that it's taken this long," says Boscoe of the Women's Health Network. "I wish Canada had shown more leadership."

The WHO includes EC on its list of essential medications. It is available without a prescription - and in some cases without a pharmacist's intervention - in 28 countries, including France, the UK, Denmark and Norway. Experiences in other countries indicate that easier access does not lead to excessive use. - Barbara Sibbald, CMAJ

Health Policy

\title{
Dosanjh to act on Canada Health Act violations
}

Published at www.cmaj.ca on Mar. 2, 2005.

Health Minister Ujjal Dosanjh will use a new dispute avoidance process when dealing with provinces accused of violating the Canada Health Act, the minister says.

"We want to make sure that we deal with these issues in a way that's amicable," Dosanjh told CMA7 in a Feb. 28 interview.

Health officials have been negotiating since last fall with $\mathrm{BC}$ and Quebec over allegations that the provinces are violating the Canada Health Act by permitting private surgeries to take place. In those provinces as well as in $\mathrm{Al}$ berta and Nova Scotia, other potential violations of the Act re-

$\sim$ volve around the existence of private MRI and other diagnostic clinics. A Canada Health Act issue dispute has also arisen in New Brunswick, which refuses to reimburse the cost of abortions carried out in private clinics.

During last September's First
Ministers' meeting on health care, all of the provinces agreed to abide by a dispute avoidance and resolution (DAR) process first drawn up in 2002. Within the next couple of weeks, there will be an announcement about the results of the discussions with the provinces, Dosanjh said.

The process requires provinces and the federal government to exchange information and discuss potential breaches of the Act. When attempts to resolve a problem are unsuccessful, the federal or a provincial health minister can set a dispute resolution process in motion.

Within 60 days of a letter being sent, governments must muster their facts, prepare a report and begin negotiations. If those negotiations are unsuccessful, either minister can refer the dispute to a 3-person panel that will provide the federal health minister with recommendations within 60 days. Then it's up to the minister to make a decision.

"Ultimately, it's the minister's responsibility and discretion to penalize provinces, dollar for dollar, for any user fees [charged patients] or queuejumping," Dosanjh said. "That's a decision I will make. But I want to make sure that we look at the DAR process and see if that can be used."

Providing more resources to the public health care system is the best way to deal with pressure for privatization of services, the minister said. Thanks to the $\$ 41$ billion over 10 years that the federal government announced after the First Ministers' meeting, provinces now have the resources they need, he said.

"We do intend to enforce the Canada Health Act. There is no doubt in my mind about that." - Laura Eggertson, CMAJ 